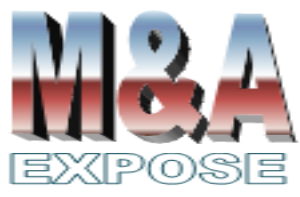

http://jurnal.usahid.ac.id/index .php/accounting

\footnotetext{
1,2Universitas Semarang

${ }^{1}$ windasarirachmawati@usm. ac.id

ªbdulkarim.akt@gmail.com
}

\section{Pengaruh Corporate Governance dan Profitabilitas terhadap Pengungkapan Islamic Social Responsibility}

\author{
Windasari Rachmawati ${ }^{1}$, Abdul Karim²
}

\section{Abstrak}

Penelitian ini bertujuan menganalisis pengaruh corporate governance dan profitabilitas terhadap Islamic Social Responsibility (ISR). ISR adalah indeks standar pelaporan kinerja sosial perusahaan berbasis syariah sebagai perluasan standar pelaporan kinerja sosial yang meliputi harapan masyarakat tidak hanya mengenai peran perusahaan dalam perekonomian, tetapi juga peran perusahaan dalam perspektif spiritual. Populasi penelitian ini adalah seluruh bank umum syariah di Indonesia. Teknik analisis yang digunakan adalah regresi linier berganda. Corporate governance diukur dengan indikator jumlah dewan komisaris dan dewan pengawas syariah. Profitabilitas diukur dengan indikator Return on Assets. ISR diukur dengan indikator Islamic Social Index. Hasil penelitian menyatakan bahwa tidak terdapat pengaruh Corporate Governance dan Profitabilitas terhadap pengungkapan ISR pada bank umum syariah di Indonesia. Direkomendasikan agar penelitian selanjutnya memperdalam analisis dengan faktor-faktor determinan lainnya pada periode waktu yang lebih panjang.

Kata kunci : Corporate Governance, Return on Assets, Islamic Social Responsibility.

\section{Abstract}

This study aims to analyze the influence of corporate governance and profitability on Islamic Social Responsibility (ISR). ISR is a standard index for reporting the social performance of sharia-based companies as an extension of social performance reporting standards that includes public expectations not only about the role of companies in the economy, but also the role of companies in a spiritual perspective. The population of this research is all Islamic commercial banks in Indonesia. The analysis technique used is multiple linear regression. Corporate governance is measured by an indicator of the number of commissioners and sharia supervisory boards. Profitability are measured by the Return on Assets indicator. ISR is measured by the Islamic Social Index indicator. The result of this research states that there is no influence of Corporate Governance and Profitability on ISR disclosure in Islamic commercial banks in Indonesia. Further research is recommended to deepen the analysis with other determinants over a longer period of time.

Keywords: Corporate Governance, Return on Assets, Islamic Social Responsibility. 


\section{PENDAHULUAN}

Sustainability Report (SR) adalah informasi perusahaan mengenai kinerja ekonomi, lingkungan dan pemerintah. Namun tidak hanya melaporkan dari data yang terkumpul, SR adalah metode untuk menginternalisasi dan memperbaiki komitmen organisasi terhadap pembangunan berkelanjutan dengan cara yang dapat ditunjukkan kepada pemangku kepentingan internal dan eksternal.

Global Reporting Initiative (GRI) adalah sebuah organisasi standar internasional yang independen. GRI selain membantu para pebisnis juga membantu pemerintah dan organisasi lain untuk mengerti dan mengkomunikasikan dampak bisnisnya dalam isu perubahan iklim, hak asasi manusia, juga korupsi. Konsep Corporate Social Responsibility (SCR) kini tidak hanya berkembang di ekonomi konvensional, tetapi juga berkembang dalam ekonomi Islam. Konsep CSR dalam Islam erat kaitannya dengan perusahaan-perusahaan yang menjalankan kegiatan bisnis sesuai dengan konsep syariah yang diharapkan perusahaan tersebut dapat melakukan tanggungjawab sosial perusahaan secara Islami. Berkembangnya CSR dalam ekonomi Islam juga turut meningkatkan perhatian masyarakat terhadap lembaga atau institusi syariah. Hal tersebut dikarenakan adanya kebutuhan masyarakat untuk mengenal secara lebih dalam terhadap lembaga atau institusi syariah, semakin besar dari waktu ke waktu.

Haniffa (2002) menyatakan bahwa selama ini pengukuran CSR disclosure pada perbankan syariah masih mengacu pada Global Reporting Initiative Index (GRI). Padahal saat ini banyak diperbincangkan mengenai Islamic Social Reporting yang sesuai dengan prinsip syariah. Peneliti-peneliti ekonomi syariah saat ini banyak yang menggunakan Islamic Social Reporting Index (ISR) untuk mengukur CSR institusi keuangan syariah. Indeks ISR berisi item-item standard CSR yang ditetapkan oleh AAOIFI (Accounting and Auditing Organization for Islamic Financial Institutions). Fitria dan Hartanti (2010) menyatakan bahwa indeks ISR diyakini dapat menjadi pijakan awal dalam hal standar pengungkapan CSR yang sesuai dengan perspektif Islam.

Othman et al. (2009) mengembangkan indeks pengungkapan yang relevan dengan hal-hal yang telah disebutkan sebelumnya pada Islamic Social Reporting (ISR) Index. Selain itu Othman et al. (2009) menentukan bahwa ukuran perusahaan, profitabilitas, dan ukuran dewan direksi muslim secara signifikan mempengaruhi tingkat pengungkapan ISR, sedangkan tipe industri bukanlah faktor penting yang mempengaruhi ISR secara signifikan. Sedangkan Khoirudin (2013) menentukan bahwa ukuran dewan komisaris terbukti memiliki pengaruh positif signifikan terhadap pengungkapan ISR pada perbankan syariah di Indonesia, sedangkan ukuran dewan pengawas syariah tidak berpengaruh.

Penelitian ini merupakan pengembangan penelitian Othman et al (2009) dan Khoirudin (2013) dengan menggunakan ISR sebagai indeks pengungkapan tanggung jawab sosial perbankan syariah disertai dengan variabel bebas. Teori legitimasi adalah salah satu teori yang mendasari pengungkapan CSR. Menurut Khoirudin (2013) teori legitimasi dapat digunakan untuk menjelaskan keterkaitan antara good corporate governance dalam hal ini adalah dewan komisaris dan dewan pengawas syariah dengan pengungkapan CSR perbankan syariah. Oleh karena itu, penulis berkeinginan untuk mengembangkan penelitian sebelumnya Khoirudin (2013) dan Othman et al. (2009) dengan menggunakan ISR sebagai indeks pengungkapan tanggung jawab sosial. Objek penelitian adalah perbankan syariah, namun disertai dengan perubahan variabel independen Dewan Direksi Muslim dengan 
variabel independen ukuran dewan direksi yang dipergunakan oleh perbankan syariah. Hal tersebut dikarenakan data agama Dewan Direksi tidak dipublikasikan secara umum di Indonesia, berbeda dengan di Malaysia yang dipublikasikannya sebagai perhitungan zakat.

\section{TINJAUAN PUSTAKA}

Islamic Social Responsibility. CSR dapat didefinisikan sebagai tanggung jawab moral suatu perusahaan terhadap para strategi stakeholdersnya, terutama komunitas atau masyarakat disekitar wilayah kerja dan operasinya (Daniri, 2008). Menurut konsep etika Islam, terbentuk akuntabilitas dalam perspektif ekonomi Islam yaitu pelaporan tanggung jawab sosial perusahaan sesuai dengan prinsip syariah. Dalam ekonomi konvensional, pelaporan tanggung jawab sosial dikenal sebagai perpanjangan dari sistem pelaporan keuangan yang merefleksikan ekspektasi sosial yang lebih luas sehubungan dengan peran masyarakat dalam ekonomi atau kegiatan bisnis perusahaan. Terkait dengan hal tersebut, Haniffa (2002) berpendapat bahwa pelaporan tanggung jawab sosial perusahaan pada sistem konvensional hanya berfokus pada aspek material dan moral. la menambahkan bahwa seharusnya aspek spiritual juga dijadikan sebagai fokus utama dalam pelaporan tanggung jawab sosial perusahaan karena para pembuat keputusan Muslim memiliki ekspektasi agar perusahaan mengungkapkan informasi-informasi terbaru secara sukarela guna membantu dalam pemenuhan kebutuhan spiritual mereka. Oleh karena itu, ia memandang bahwa perlu adanya kerangka khusus untuk pelaporan pertanggungjawaban sosial yang sesuai dengan prinsip Islam.

Corporate Governance. Fitria \& Hartanti (2010) menyatakan bahwa indeks ISR diyakini dapat menjadi pijakan awal dalam hal standar pengungkapan CSR yang sesuai dengan perspektif Islam. Istilah pengungkapan dalam akuntansi mengacu pada penyajian dan pengungkapan laporan keuangan perusahaan. Dalam penelitian ini item yang diungkapkan dalam ISR adalah 44 item yang dijadikan pengungkapan. Teori legitimasi adalah salah satu teori yang mendasari pengungkapan CSR. Berdasarkan teori legitimasi dapat digunakan untuk menjelaskan keterkaitan antara struktur corporate governance, dalam hal ini dewan komisaris dan dewan pengawas syariah dengan pengungkapan CSR perbankan syariah. Berdasarkan uraian di atas, maka hipotesis yang diajukan adalah sebagai berikut:

H1: Corporate Governance berpengaruh positif terhadap pengungkapan Islamic Social Responsibility.

Dewan komisaris. Ukuran dewan komisaris yaitu jumlah anggota dewan komisaris dalam suatu perusahaan (Sembiring, 2005). Semakin banyak jumlah dewan komisaris, maka pengawasan akan semakin baik. Dengan pengawasan yang baik, maka diharapkan pengungkapan ISR akan semakin luas karena dapat meminimalisir informasi yang mungkin dapat disembunyikan oleh manajemen. Hasil penelitian Sembiring (2005) serta Veronica \& Sumin (2009) menunjukkan bahwa proporsi dewan komisaris mempengaruhi tingkat pengungkapan CSR. Penelitian Khoirudin (2013) menyimpulkan bahwa dewan komisaris terbukti berpengaruh positif signifikan terhadap pengungkapan tanggung jawab sosial. Semakin besar ukuran dewan komisaris maka pengawasan akan semakin baik. Hal ini sejalan dengan penelitian Sembiring (2005) dan Utami (2007) yang menunjukkan bahwa proporsi dewan komisaris mempengaruhi pengungkapan tanggung jawab sosial. 
Dewan Pengawas Syariah. Menurut Lewis et al. (2004) yang pokok dalam kerangka Corporate Governance untuk sebuah Bank Syariah adalah Dewan Pengawas Syariah (DPS) dan kontrol internal yang mendukungnya. DPS adalah badan independen yang ditempatkan oleh Dewan Syariah Nasional (DSN) pada Bank Syariah, Unit Usaha Syariah maupun institusi keuangan syariah lainnya. Anggota DPS harus terdiri dari pakar di bidang syariah muamalah yang juga memiliki pengetahuan umum di bidang perbankan. Penelitian Khoirudin (2013) menemukan bahwa DPS tidak terbukti berpengaruh signifikan terhadap pengungkapan tanggung jawab sosial. Hal ini sejalan dengan penelitian Rizkianingsih (2012) bahwa Islamic Governance Score tidak berpengaruh terhadap pengungkapan ISR, karena masih kurangnya pengawasan dewan pengawas syariah terhadap ISR.

Profitabilitas. Pengungkapan pertanggungjawaban sosial perusahaan mencerminkan suatu pendekatan perusahaan dalam melakukan adaptasi dengan lingkungan yang dinamis dan bersifat multidimensi. Penelitian terdahulu lebih banyak menggunakan rasio Return on Equity (ROE), Return on Asset (ROA), dan Net Profit Margin (NPM) sebagai proksi profitabilitas (Haniffa \& Cooke, 2005; Alsaeed, 2006; Hossain \& Hammami, 2009). Adapun Othman et al. (2009) menggunakan laba sebelum pajak sebagai proksi profitabilitas. Berdasarkan hasil penelitian sebelumnya diketahui bahwa profitabilitas mempengaruhi besarnya pengungkapan yang dilakukan perusahaan. Othman et al. (2009) juga menyimpulkan bahwa laba sebelum pajak perusahaan berpengaruhi postif terhadap tingkat pengungkapan ISR. Dalam penelitian ini digunakan ROA sebagai proksi yang merupakan rasio pengelolaan aktiva. Berdasarkan uraian di atas, maka hipotesis yang diajukan adalah sebagai berikut:

H2: Return On Asset berpengaruh positif terhadap pengungkapan Islamic Social Responsibility.

\section{METODE PENELITIAN}

Penelitian ini merupakan penelitian kuantitatif, data yang digunakan adalah data sekunder. Studi dokumenter dilakukan dengan mengumpulkan data sekunder yang berupa data laporan keuangan tahunan perusahaan periode 2015-2019 yang diperoleh dari laporan tahunan bank umum syariah.

Tahapan penelitian ini yakni mencari informasi yang lebih mendalam pada informasi penelitian untuk melakukan need assessment (Price el al., 2010). Need assessment adalah metode pendekatan formal pengumpulan data untuk mengidentifikasi kebutuhan dari kelompok atau individu. Need assesment terkait pengungkapan ISR meliputi 43 item, di mana awal mula adanya ISR dari kegiatan perbankan syariah pada tanggung jawab sosialnya yaitu program CSR. Berdasarkan data laporan tahunan perbankan syariah tahun 2015-2019 dan penelitian terdahulu, maka peneliti menganalisis pengaruh faktor Corporate Governance dan profitabilitas perbankan syariah dalam pengungkapan ISR.

Populasi penelitian ini meliputi bank syariah yang terdaftar di Bank Indonesia berjumlah 14 bank syariah. Metode pemilihan sampel yang digunakan adalah purposive sampling, yaitu pengambilan sampel berdasarkan keperluan penelitian yang artinya setiap unit yang diambil dari populasi dipilih dengan sengaja berdasarkan kriteria tertentu (Purwanto, 2017). Dalam hal ini peneliti memilih informan yang dianggap mengetahui permasalahan dan dapat dipercaya untuk menjadi sumber data yang memiliki kebenaran 
dan pengetahuan yang mendalam. Namun demikian, informan yang dipilih dapat menunjukkan informan lain yang dipandang lebih tahu. Maka pilihan informan dapat berkembang sesuai dengan kebutuhan dan kemantapan peneliti dalam memperoleh data (Sutopo, 2002).

Teknik purposive sampling digunakan atas dasar teknik ini dipandang mampu menangkap kedalaman data dalam menghadapi realitas jamak dan tidak dimaksudkan untuk membuat generalisasi tetapi untuk kedalaman penelitian dalam konteks tertentu. Adapun kriteria tersebut antara lain:

1. Sampel merupakan Bank Umum Syariah (BUS) yang terdaftar di Bank Indonesia secara berturut-turut pada periode tahun 2015-2019.

2. Bank Umum Syariah (BUS) yang mempublikasikan laporan keuangan tahunan dalam website BUS atau website resmi lainnya periode tahun 2015-2019.

3. Bank Umum Syariah (BUS) yang mempublikasikan laporan pelaksanaan Good Corporate Governance dalam website resmi BUS periode tahun 2015-2019.

4. Mengungkapkan data-data yang berkaitan dengan variabel penelitian dan tersedia lengkap data tahun 2015-2019.

Menurut Moleong (2000), analisa data adalah proses mengorganisasikan dan mengurutkan data ke dalam pola, kategori, dan satuan uraian dasar sehingga dapat ditemukan tema dan dapat dirumuskan hipotesis kerja, seperti yang disarankan oleh data. Teknik analisa data merupakan suatu langkah yang paling menentukan dari suatu penelitian, karena analisa data berfungsi untuk menyimpulkan hasil penelitian. Teknik analisis data penelitian ini menggunakan regresi linier berganda.

Dalam analisis regresi linier berganda, juga dilakukan uji hipotesis dengan uji $F$ dan uji t. Uji F digunakan untuk menguji signifikansi model regresi. Uji $F$ akan membuktikan secara statistik bahwa keseluruhan koefisien regresi yang digunakan dalam analisis ini signifikan. Apabila nilai signifikansi $F$ lebih kecil dari 0,05 maka model regresi signifikan secara statistik. Adapun uji t menunjukkan seberapa jauh pengaruh variabel independen secara individual dalam menerangkan variasi variabel dependen. Jika tingkat signifikansi nilai $\mathrm{t}$ lebih kecil daripada 0,05 maka dapat disimpulkan bahwa hipotesis diterima, dan sebaliknya (Ghozali, 2011).

\section{HASIL DAN PEMBAHASAN}

Analisis deskriptif atas data semua variabel dalam kurun waktu 2015-2019 berdasarkan minimum, maximum, mean dan standard deviasi adalah sebagai berikut:

Tabel 1. Analisis Deskriptif

\begin{tabular}{lrrrrr}
\hline & N & Minimum & Maximum & Mean & Std. Deviation \\
\hline Ukuran Dewan Komisaris & 70 & 3,00 & 6,00 & 3,7857 &, 94628 \\
Ukuran Dewan Pengawas & 70 & 1,00 & 4,00 & 2,1429 &, 64349 \\
$R O A$ & 70 & $-2,40$ & 2,83 & 1,4651 &, 84005 \\
Islamic Social Responsibility & 70 &, 00 & 1,00 &, 8571 &, 35245 \\
\hline
\end{tabular}

Sumber : data diolah, 2020. 
Ukuran dewan komisaris berkisar antara tiga hingga enam orang. Ukuran dewan pengawas Syariah berkisar antara satu hingga empat orang. Return on Assets berkisar dari -2,40 hingga 2,83. Adapun ISR ada yang mengungkapkan dan ada yang tidak mengungkapkan.

Uji Asumsi Klasik. Uji normalitas bertujuan menguji apakah dalam model regresi, variabel dependen dan variabel independen berdistribusi normal atau tidak. Tes statistic yang digunakan antara lain analisis grafik histogram, normal probability plots dan Kolmogorov-Smirnov test (Ghozali, 2001). Kriteria Kolmogorov-Smirnov test adalah jika $p$ value (Asymp.Sig) > 0,05 maka data berdistribusi normal, dan sebaliknya. Hasil pengujian normalitas pada Tabel 2 menunjukkan bahwa nilai Kolmogrov-Smirnov untuk pengungkapan ISR sigfikansinya $<0,05$ atau dengan kata lain residual berdistribusi normal.

Tabel 2. Uji Normalitas

\begin{tabular}{llr}
\hline & & Unstandardized Residual \\
\hline $\mathrm{N}$ & & 70 \\
Normal Parameters & Mean &, 0000000 \\
& Std. Deviation & 1,58669343 \\
Most Extreme Differences & Absolute &, 140 \\
& Positive &, 140 \\
& Negative &,- 091 \\
Kolmogorov-Smirnov Z & & 1,171 \\
Asymp. Sig. (2-tailed) & & 0,129 \\
\hline
\end{tabular}

Sumber : data diolah, 2020.

Uji multikolinieritas bertujuan untuk menguji apakah dalam model regresi ditemukan adanya korelasi antara variabel indepen (Ghozali, 2011). Indikator multikolinieritas dapat dilihat dari nilai tolerance dan VIF (Variance Inflation Factor). Untuk bebas dari masalah multikolinieritas, nilai tolerance harus $\geq 0,1$ dan nilai VIF $<10$ (Ghozali, 2011). Hasil uji multikolinearitas dalam Tabel 3 menunjukkan bahwa ketiga variabel independen tidak terjadi multikolonieritas karena nilai tolerance $\geq 0,1$ dan nilai VIF $<10$. Dengan demikian ketiga variabel independen (ukuran dewan komisaris, ukuran Dewan Pengawas Syariah, dan ROA) dapat digunakan untuk memprediksi ISR selama periode pengamatan.

Tabel 3. Uji Multikolinearitas

\begin{tabular}{|c|c|c|c|c|c|c|c|c|}
\hline & \multirow[t]{2}{*}{ Model } & \multicolumn{2}{|c|}{$\begin{array}{l}\text { Unstandardized } \\
\text { Coefficients }\end{array}$} & \multirow{2}{*}{$\begin{array}{c}\text { Standardized } \\
\text { Coefficients }\end{array}$} & \multirow[t]{2}{*}{$\mathbf{t}$} & \multirow[t]{2}{*}{ Sig. } & \multicolumn{2}{|c|}{$\begin{array}{l}\text { Collinearity } \\
\text { Statistics }\end{array}$} \\
\hline & & B & Std. Error & & & & Tolerance & VIF \\
\hline \multirow[t]{4}{*}{1} & (Constant) & ,615 & ,216 & & 2,846 & ,006 & & \\
\hline & VAR00001 & ,004 & ,047 & 010 & ,075 & ,940 & 888 & 1,126 \\
\hline & VAR00002 & ,121 & ,069 & ,22 & 1,749 &, 085 & ,895 & 1,117 \\
\hline & VAR00003 &,- 021 & ,051 &,- 051 &,- 417 & ,678 & ,958 & 1,044 \\
\hline
\end{tabular}

Sumber : data diolah, 2020.

Uji heteroskedastisitas dalam penelitian ini menggunakan uji Glejser. Uji ini dilakukan dengan meregresikan nilai absolute residual terhadap variabel independen. Jika variabel independen signifikan mempengaruhi variabel dependen (absolute residual), maka ada indikasi terjadi heteroskedastisitas. Model regresi yang baik adalah yang homoskedastisitas atau tidak terjadi heteroskedastisitas. Deteksi permasalahan heteroskedasitas antara lain 
dengan diagram scatterplot, yang menyatakan apabila grafik membentuk pola khusus maka model terjadi heteroskedasitas. Akan tetapi jika ada pola yang jelas, serta titik-titik menyebar si atas dan di bawah angka 0 pada sumbu $Y$, maka tidak terjadi heteroskedastisitas. Diagram scatterplot pada Gambar 1 berikut memperlihatkan bahwa titik-titik pada grafik tidak membentuk pola tertentu yang jelas, di mana titik-titik menyebar di atas dan di bawah angka 0 pada sumbu $Y$, sehingga grafik tersebut tidak dapat dibaca dengan jelas. Hasil ini memperlihatkan bahwa tidak terjadi heteroskedasitas dalam model penelitian ini.

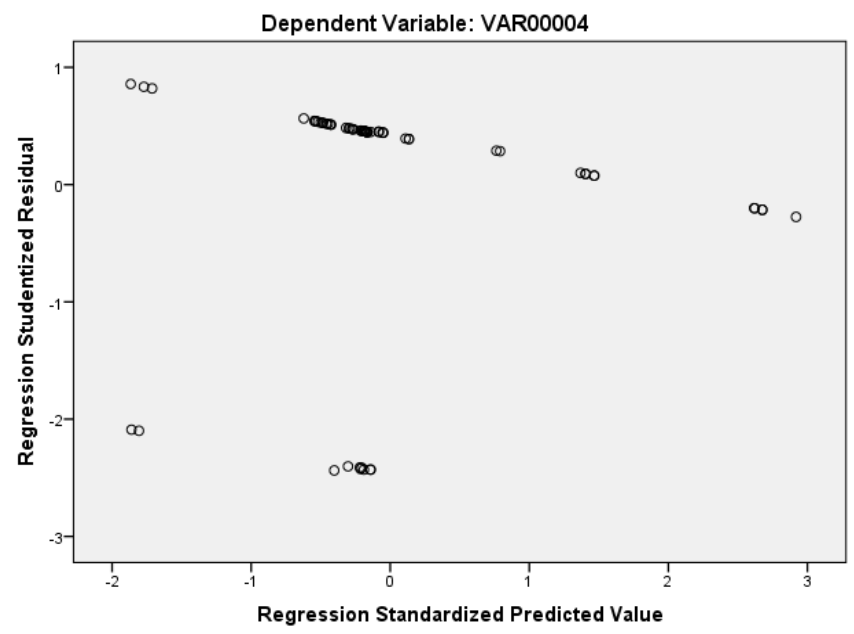

Gambar 1. Scatter Plot Diagram

Sumber: output SPSS, data diolah, 2020

Autokorelasi dikenal juga dengan nama korelasi serial dan sering ditemukan pada data serial waktu. Uji autokorelasi bertujuan menguji apakah dalam model regresi terdapat korelasi antara kesalahan penggunaan pada periode t dengan kesalahan penggunaan pada periode $\mathrm{t}-1$ (sebelumnya). Model regresi yang baik adalah regresi yang bebas dari autokorelasi. Indikator untuk mendeteksi autokorelasi adalah Uji Durbin Watson (D-W). Hasil uji autokorelasi pada tabel 4 menunjukkan nilai DW sebesar 1,968 maka DW 1,968 > DU 1,75960 sehingga tidak terdapat masalah autokorelasi dalam model penelitian ini.

Tabel 4. Uji Autokorelasi

\begin{tabular}{|c|c|c|c|c|c|c|c|c|c|c|}
\hline \multirow[b]{2}{*}{ Model } & \multirow[b]{2}{*}{ R } & \multirow[b]{2}{*}{$\begin{array}{c}\mathrm{R} \\
\text { Square }\end{array}$} & \multirow[b]{2}{*}{$\begin{array}{l}\text { Adjusted R } \\
\text { Square }\end{array}$} & \multirow[b]{2}{*}{$\begin{array}{l}\text { Std. Error of } \\
\text { the Estimate }\end{array}$} & \multicolumn{5}{|c|}{ Change Statistics } & \multirow[b]{2}{*}{$\begin{array}{l}\text { Durbin- } \\
\text { Watson }\end{array}$} \\
\hline & & & & & $\begin{array}{l}\text { R Square } \\
\text { Change }\end{array}$ & $\begin{array}{c}F \\
\text { Change }\end{array}$ & df1 & df2 & $\begin{array}{c}\text { Sig. F } \\
\text { Change }\end{array}$ & \\
\hline 1 & ,225a & 051 & ,008 & ,35110 & 051 & 1,178 & 3 & 66 & ,325 & ,968 \\
\hline
\end{tabular}

Sumber: data sekunder, 2020.

Untuk menguji hipotesis yang ada pada penelitian ini perlu dilakukan analisis statistik terhadap data yang telah diperoleh. Analisis statistik yang digunakan dalam penelitian ini adalah regresi linier berganda. Ghozali (2011) menyatakan bahwa dalam analisis regresi linier berganda, uji $\mathrm{t}$ dan uji $\mathrm{F}$ sangat dipengaruhi nilai residual yang mengikuti distribusi normal, sehingga jika asumsi ini menyimpang maka uji stastistik menjadi tidak valid. Oleh karena itu, jika terdapat data yang menyimpang dari sebarannya, maka data tersebut tidak disertakan dalam analisis. 
Analisis regresi linier berganda menguji pengaruh beberapa variabel independen terhadap variabel dependen (Ghozali, 2019) sebagaimana dinyatakan dalam Tabel 5 berikut:

Tabel 5. Analisis Regresi Linier Berganda

\begin{tabular}{|c|c|c|c|c|c|}
\hline \multirow[t]{2}{*}{ Model } & \multicolumn{2}{|c|}{$\begin{array}{l}\text { Unstandardized } \\
\text { Coefficient }\end{array}$} & \multirow{2}{*}{$\begin{array}{c}\begin{array}{c}\text { Standardized } \\
\text { Coefficient }\end{array} \\
\text { B }\end{array}$} & \multirow[t]{2}{*}{$\mathbf{t}$} & \multirow[t]{2}{*}{ Sig. } \\
\hline & B & Std. Error & & & \\
\hline Constant & ,615 & ,216 & & 2,846 & 0,006 \\
\hline Ukuran dewan komisaris & 004 & 047 & 010 & 0,075 & 0,940 \\
\hline Ukuran dewan pembina & 121 & ,069 & 222 & 1,749 & 0,085 \\
\hline Return on Asset &,- 021 & 051 &,- 051 &,- 417 & 0,678 \\
\hline
\end{tabular}

Sumber : data diolah, 2020.

Berdasarkan Tabel 5 persamaan regresi adalah :

$Y=\alpha+\beta 1+\beta 2+\beta 3+e$

$Y=0,615+0,004 \beta_{1}+0,121 \beta_{2}+-0,021 \beta_{3}+e$

Koefisien persamaan regresi linier berganda serta uji signifikansi t dapat diartikan sebagai berikut:

1. Koefisien regresi ukuran dewan komisaris sebesar 0,004 dengan signifikansi $>0,05$ artinya ukuran dewan komisaris tidak berpengaruh signifikan terhadap pengungkapan Islamic Social Responsibility bank syariah. Ini bertentangan dengan penelitian Khoirudin (2013) yang mengungkapkan bahwa ukuran dewan komisaris berpengaruh positif signifikan terhadap pengungkapan Islamic Social Reporting pada perbankan syariah.

2. Koefisien regresi ukuran Dewan Pembina Syariah 0,121 dengan signifikansi $>0,05$ artinya ukuran Dewan Pembina Syariah tidak berpengaruh signifikan terhadap pengungkapan Islamic Social Responsibility bank syariah. Hal ini sejalan dengan penelitian Rosiana (2015) yang menunjukkan para investor tidak begitu memperhatikan informasi tentang corporate governance ketika melakukan investasi di perusahaan, karena kualitas pengungkapan Islamic Social Reporting masih sangat rendah.

3. Koefisien regresi ROA sebesar $-0,021$ dengan signifikansi $>0,05$ artinya ROA tidak berpengaruh signifikan terhadap pengungkapan Islamic Social Responsibility bank syariah. Penelitian ini mendukung penelitian Othman, et al. (2009) yang menyimpulkan bahwa Profitabilitas tidak berpengaruh terhadap pengungkapan Islamic Social Responsibility.

Selanjutnya pengujian signifikansi $F$ mengenai pengaruh simultan variabel independen terhadap variabel dependen menunjukkan nilai $F$ hitung sebesar 1,178 dengan signifikansi 0,0000 . Hal ini bermakna bahwa variabel ukuran dewan komisaris, ukuran dewan pembina Syariah, dan profitabilitas secara simultan berpengaruh signifikan terhadap pengungkapan Islamic Social Responsibility.

Koefisien determinasi pada Tabel 6 berikut menggambarkan seberapa besar perubahan atau variasi variabel dependen yang dapat dijelaskan oleh perubahan atau variasi variabel independen : 
Pengaruh Corporate Governance dan Asset...

Windasari Rachmawati, Abdul Karim

Tabel 6. Koefisien Determinasi

\begin{tabular}{cccc}
\hline Model & $\mathrm{R}$ & $\mathrm{R}$ Square & Adjusted R Square \\
\hline 1 & $.225^{\mathrm{a}}$ & .008 & .35110 \\
\hline
\end{tabular}

Sumber : data diolah, 2020.

Berdasarkan tabel 6 tersebut dapat dilihat bahwa koefisien determinasi (Adjusted $R$ Square) sebesar 0,3511. Hal ini menunjukkan bahwa jumlah dewan komisaris, jumlah dewan pembina syariah, dan profitabilitas dapat menjelaskan variasi pengungkapan Islamic Social Responsibility sebesar 35,11 persen, sedangkan sebesar 64,89 persennya dijelaskan oleh variabel-variabel lain di luar model penelitian ini.

\section{KESIMPULAN}

Berdasarkan hasil analisis dan pembahasan yang dilakukan maka dapat ditarik kesimpulan bahwa :

1. Corporate Governance yang diukur dengan indikator ukuran dewan komisaris dan ukuran dewan pembina syariah tidak berpengaruh signifikan terhadap pengungkapan Islamic Social Responsibility.

2. Profitabilitas yang diukur dengan indikator Return On Asset tidak berpengaruh signifikan terhadap pengungkapan Islamic Social Responsibility.

3. Ukuran dewan komisaris, ukuran dewan pembina syariah, dan profitabilitas secara simultan berpengaruh signifikan terhadap pengungkapan Islamic Social Responsibility.

Penelitian ini masih mempunyai beberapa keterbatasan antara lain hanya menggunakan populasi bank syariah yang terdaftar di Bank Indonesia pada periode 20152019. Penelitian selanjutnya direkomendasikan agar memperpanjang periode pengamatan serta menambah variabel independen yang relevan mempengaruhi pengungkapan Islamic Social Responsibility bagi bank syariah di Indonesia.

\section{DAFTAR PUSTAKA}

Farook, S. Z., \& Lanis, R. (2005). Banking on Islam? Determinants of CSR Disclosure. Proceedings on International Conference on Islamic Economics and Finance.

Farook, S. (2007). On Corporate Social Responsibility of Islamic Financial Institutions. Islamic Economic Studies, 15(1).

Fitria, S. \& Hartanti, D. (2010). Islam dan Tanggung Jawab Sosial: Studi Perbandingan Pengungkapan Berdasarkan Global Reporting Initiative Indeks dan Islamic Social Reporting Indeks. Prosiding Simposium Nasional Akuntansi 13-Purwokerto.

Forum Corporate Governance Indonesia. (2001). Corporate Governance: Tata Kelola Perusahaan. Edisi Ketiga: Jakarta.

Ghozali, I. (2011). Aplikasi Analisis Multivariate dengan Program IBM SPSS 19. Semarang : Universitas Diponegoro.

Haniffa, R. (2002). Social Reporting Disclosure : An Islamic Perspective. Indonesian Management Research, 128-146. 
Khoirudin. (2013). Corporate Governance dan Pengungkapan Islamic Social Reporting pada Perbankan Syariah di Indonesia. Jurnal Dinamika Manajemen, 2(2).

Othman, R., Thani, A. M., \& Ghani, E. K. (2009). Determinants of Islamic Social Reporting Among Top Sharia-Approved Companies in Bursa Malaysia. Research Journal of International Studies. 12.

Peraturan Bank Indonesia No. 11/33/PBI/2009 tentang Pelaksanaan Good Corporate Governance bagi Bank Umum Syariah dan Unit Usaha Syariah.

Rita R., Arifin, B., Hamdani, M. (2015). Pengaruh Ukuran Perusahaan, Profitabilitas, Leverage, dan Islamic Governance Score Terhadap Pengungkapan Islamic Social Reporting. Jurnal Bisnis dan Manajemen, 5(1). 